\title{
Homing of pelagic fish to fish aggregation devices (FADs): the role of sensory cues
}

\author{
Tim Dempster ${ }^{1, *}$, Michael J. Kingsford ${ }^{2}$ \\ ${ }^{1}$ School of Biological Sciences, University of Sydney, New South Wales 2006, Australia \\ ${ }^{2}$ Reef and Ocean Ecology Laboratory, School of Marine Biology and Aquaculture, James Cook University, Townsville, \\ Queensland 4811, Australia
}

\begin{abstract}
We conducted a displacement experiment to determine the influence of sensory cues on homing of pelagic fish to fish aggregation devices (FADs). If pelagic fish use chemical cues to home to a FAD, and cues such as odours from fouling organisms and fish associated with the FAD only occur down-current, we hypothesised that fish released down-current from a FAD would return in higher proportions than fish released across-current. Coryphaena hippurus $(\mathrm{n}=161)$ and Seriola lalandi $(\mathrm{n}=31$ ) were caught from January to May in 2000, 2001 and 2002 within $50 \mathrm{~m}$ of a FAD and displaced to release sites 20, 75, 275 or 500 m across- or down-current. Overall proportions of return of C. hippurus to FADs varied among the 3 yr, with returns highest in 2000 (48.3\%), lowest in 2001 $(7.6 \%)$ and intermediate in $2002(33 \%)$. There was a strong relationship between abundance of $C$. hippurus around FADs and current speeds, possibly due to a behavioural shift towards closer association with FADs during strong currents. This may have affected the proportions of return in different years, as currents were strongest in $2000\left(0.46 \mathrm{~m} \mathrm{~s}^{-1} \pm 0.06\right)$, weakest in $2001\left(0.13 \mathrm{~m} \mathrm{~s}^{-1} \pm 0.02\right)$ and intermediate in $2002\left(0.30 \mathrm{~m} \mathrm{~s}^{-1} \pm 0.09\right)$. Both C. hippurus and $S$. lalandi returned in proportions significantly higher than could be expected if fish swam in a random direction from the point of release, indicating a directed homing behaviour. Returns from down- and across-current release sites were similar at all distances for $C$. hippurus and $S$. lalandi, providing no evidence to suggest that these species used only chemical cues to home to FADs. As fish returned from up to $275 \mathrm{~m}$ away, sensory processes other than vision and olfaction must operate. Sound or vibrations from associated fish and the FAD are possible cues for homing.
\end{abstract}

KEY WORDS: Chemical cues · Coryphaena hippurus · Currents · FAD · Homing · Pelagic fish · Seriola lalandi $\cdot$ Temperature

Resale or republication not permitted without written consent of the publisher

\section{INTRODUCTION}

Floating structures in the open ocean such as logs, seaweed rafts and man-made fish aggregation devices (FADs) are widely recognised for their capacity to attract pelagic fish (Hunter \& Mitchell 1967, Kingsford 1993; Higashi 1994). Their use in commercial fisheries is widespread; over $1000000 \mathrm{t}$ of tuna and $100000 \mathrm{t}$ of by-catch are caught each year in the Atlantic, Indian and Pacific oceans around FADs (Fonteneau et al. 2000), which is greater than $1 \%$ by weight of the world's capture fishery (Fisheries and Agriculture Organization [FAO] 1999, available at: www.fao.org/fi/
statist/FISOFT/FISHPLUS.asp). Increased use of FADs for pelagic fisheries over the past decade has dramatically shifted patterns of stock exploitation. Large catches of small tuna around FADs could lead to recruitment overfishing of some tuna stocks (Fonteneau et al. 2000). With such important management implications, a greater understanding of the processes influencing the attraction of fish to FADs is essential.

There has been great speculation on the processes influencing the attraction of fish to FADs in the open ocean and few manipulative experiments have been done (Kingsford 1999). Vision, odour, sound, or magnetic cues may be involved. Vision has long been 
thought to be important in the association of fish with FADs, based on early experimental work by Hunter \& Mitchell (1967). However, fish have been shown to swim to distances well beyond their sight of FADs and yet still relocate them (Holland et al. 1990, Ibrahim et al. 1990, Dagorn et al. 2000), suggesting that other mechanisms drive association. Sound generated by FADs is a potential cue, however, whether fish have the ability to detect the location of a sound source with sufficient sensitivity to navigate is uncertain (for review see Popper et al. 2003). Moreover, knowledge of the hearing capabilities of large pelagic fish is poor, and appropriate experiments to test the importance of sound are difficult in the open ocean.

Magnetic cues are important for long-distance navigation (10s to 1000 s of kilometers) in the ocean by turtles (Lohmann \& Lohmann 1996), salmon (Quinn et al. 1981) and some elasmobranchs (Klimley 1993). Yellowfin tuna Thunnus albacares, a FAD-associated species, has cranial biogenic magnetite (Walker et al. 1984), suggesting the presence of a magnetic sense organ (Walker et al. 1997), and can discriminate between magnetic fields of different intensities (Walker 1984). Direct movements between FADs spaced up to $18 \mathrm{~km}$ apart, indicating an ability to navigate to FADs at the scale of kilometers to 10s of kilometers, have also been reported (Holland et al. 1990, Dagorn et al. 2000). However, the use of magnetic cues for navigation by fish over distances less than a few $\mathrm{km}$ seems unlikely, as direction and intensity of the Earth's magnetic field generally vary little over such short spatial scales (Walker et al. 1997, Doving \& Stabell 2003).

Odours are important sensory stimuli in the ocean and pelagic fish can detect certain amino acids at extremely low concentrations (Atema et al. 1980, Kobayashi \& Fujiwara 1987, Doving \& Stabell 2003). While an acute sense of smell helps fish find food (Atema et al. 1980, Kobayashi \& Fujiwara 1987), it may also enable them to locate FADs. Both marine growth on FADs and fish located around FADs produce odours that fish may use to navigate back to FADs from beyond visual range. Chemical cues may be detectable over a scale of $100 \mathrm{~s}$ of meters to kilometers (Kingsford et al. 2002), depending on the strength of directional flow.

The objective of this study was to assess the ability of pelagic fish to detect FADs and the role of chemotaxis in detection. We designed a displacement experiment to test if fish exhibited directed homing behaviour to FADs from different distances. We further tested the hypothesis that fish released down-current of FADs would return in higher proportions than fish released across-current. With directional flow, we assumed that chemical cues from both fouling organisms on the FADs and the assembled fish themselves would occur down-current of the buoy and be absent acrosscurrent. If chemotaxis was important, therefore, then the greatest return of tagged fish would be expected from releases made down-current.

\section{MATERIALS AND METHODS}

Study sites. Two oceanic weather buoys (NWAV, SWAV), hereafter also called fish aggregation devices (FADs), moored in $100 \mathrm{~m}$ of water on the continental shelf off Sydney, New South Wales (Fig. 1), were used as the study sites. The buoys provide wave height data, and are semi-permanent structures. Schools of the common dolphinfish Coryphaena hippurus and kingfish Seriola lalandi regularly associate with these structures throughout the summer and autumn months (Dempster 2003). In 2000, both SWAV and NWAV were present, whereas in 2001 and 2002 only SWAV was present.

To determine if environmental variables may have influenced experimental outcomes, measurements of current and temperature were made on each experimental day. Surface current strength and direction at each FAD were measured with a small drogue suspended at a depth of $1 \mathrm{~m}$ and marked on the surface by a small white float to minimise wind effect. The drogue

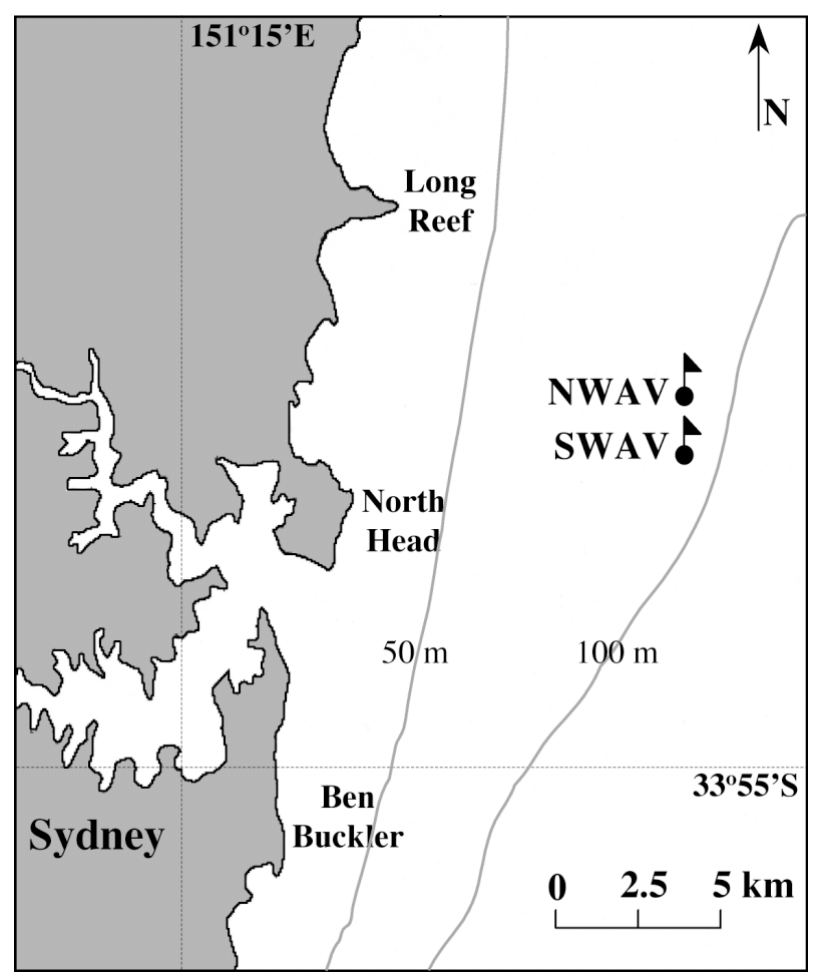

Fig. 1. Map of the locations of the fish aggregation devices (FADs) (NWAV, SWAV) on the continental shelf off Sydney, Australia 
was dropped next to the FAD and collected after a minimum of 5 min drift time, or after it had drifted at least $300 \mathrm{~m}$ down-current. Initial and final positions of the drogue were recorded with a hand-held global positioning system (GPS, Garmin 48) that had an accuracy of $\pm 20 \mathrm{~m}$. Estimates of current speeds and directions assumed a straight-line trajectory of the drogue throughout the drift. There was no evidence that drogues were caught in eddies. Hourly sea surface temperatures (SSTs) were measured at SWAV by a thermometer at $0.5 \mathrm{~m}$ depth. The hourly data was used to produce a daily average. Due to the proximity of NWAV to SWAV (approx. $1 \mathrm{~km}$ ), we assumed SSTs measured at SWAV would be indicative of those at NWAV. The percentage cover of fouling organisms on the under-surface of each FAD was determined on each day with a $30 \times 30 \mathrm{~cm}$ quadrat with a 30-point grid ( $\mathrm{n}=5$ quadrats)

Fish displacement experiment. In this study, we considered 'homing' as 'any movement taken to reach a spatially restricted area which is known to an animal' (Papi 1992). To test whether the proportion of fish that returned from each distance was greater than could be expected if fish swam in a random direction from the point of release, we modelled expected percentages of

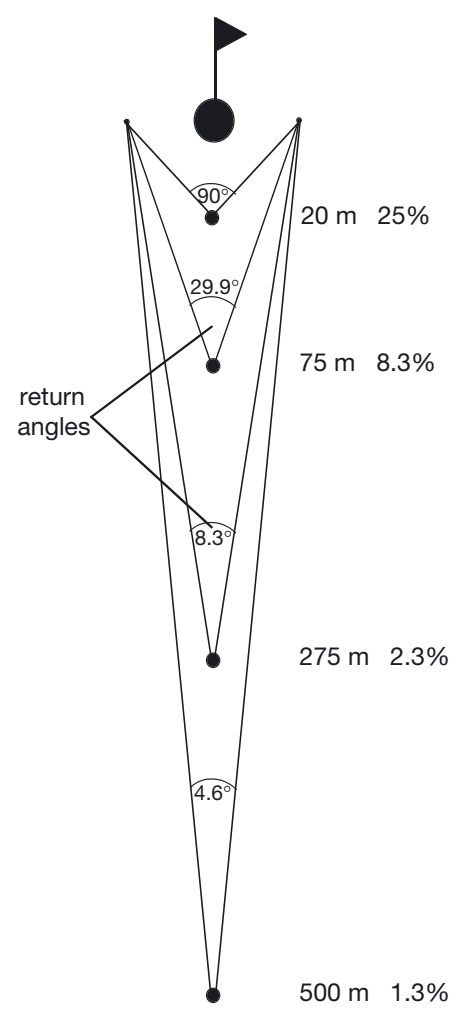

Fig. 2. Model of expected return percentages of fish released at $20,75,275$ and $500 \mathrm{~m}$ from fish aggregation devices (FADs), if fish swim in a random direction from the release point and assuming they can locate FADs visually from a distance of $20 \mathrm{~m}$ returns (Fig. 2). We assumed that fish could visually locate FADs from $20 \mathrm{~m}$, based on knowledge of visual capabilities of tuna (Nakamura 1968). Furthermore, since fish have higher contrast sensitivity to large objects than humans (Northmore et al. 1978), we assumed that a large object like a FAD was clearly in the visual range of a fish, if it was visible to the diver (K. Freitsches pers. comm.) and $20 \mathrm{~m}$ was the most common visibility range on experimental days. Therefore, if fish swam within a certain 'return angle' from the point of release that took them to within $20 \mathrm{~m}$ of either side of the FAD, we assumed successful re-association had occurred and that these fish could be seen by the diver. Return angles were divided by $360^{\circ}$ to give the expected return percentages of $25 \%$ at $20 \mathrm{~m}, 8.3 \%$ at 75 $\mathrm{m}, 2.3 \%$ at $275 \mathrm{~m}$ and $1.3 \%$ at $500 \mathrm{~m}$ (Fig. 2). Observed rates of return could then be tested against these expected values, to determine if return rates were higher than expected from random swimming. Our null hypothesis was that if fish swam in a random direction from the point of release, observed and expected values of return and no return would not differ.

If rates of return were greater than expected by random chance, sensory cues may play an important role in moored FAD detection. We tested the hypothesis that fish released down-current of FADs, where chemical cues should be present, would return to FADs in higher proportions than fish released at across-current release sites. We assumed that, with directional flow, chemical cues from both fouling organisms and FADassociated fish would occur in a down-current plume and be absent across-current.

Tagging. Juvenile dolphinfish Coryphaena hippurus and kingfish Seriola lalandi were caught on hook and line within $50 \mathrm{~m}$ of a FAD, where we assumed they would be associated with the structure. Fish were caught with lures or on hooks baited with pilchard Neopilchardus australis, retrieved quickly (between 1 and $3 \mathrm{~min}$ ) and placed in a container of water on board where they were measured (fork length: FL) and tagged. Fish were allowed to recover for 3 to $5 \mathrm{~min}$ before release. Tagging was carried out from March to April 2000, from February to May 2001, and from January to April 2002. Fish were tagged in the anterior dorsal musculature with standard $11 \mathrm{~cm}$ nylon-head dart tags (Hallprint). Extra colours (black, red and white) were added to the yellow tags with $1.5 \mathrm{~mm}$ diameter heat-shrink plastic tubing to allow for identification of individuals (Lowry \& Suthers 1998). Each tag had a distinct 3-colour combination. If the same colour combination was used twice in the same year, the 2 individuals in question were tagged on opposite sides of the body.

Over the 3 years, 161 Coryphaena hippurus (35 to $65 \mathrm{~cm} \mathrm{FL}$ ) and 31 Seriola lalandi (30 to $55 \mathrm{~cm} \mathrm{FL)} \mathrm{were}$ tagged and released in the vicinity of FADs. Substan- 
tial numbers of $C$. hippurus ( $\mathrm{n}=24$ to 79 ) were tagged in each year, with the majority of $S$. lalandi $(\mathrm{n}=28)$ tagged in 2002. Numbers of fish caught and released on experimental days varied from 1 to 16 for C. hippurus and 1 to 7 for $S$. lalandi.

Translocation and visual recapture. In 2000, fish were released at 2 orientations to the buoy, downcurrent or across-current, and at 1 of 3 distances, $20 \pm$ $5 \mathrm{~m}, 75 \pm 20 \mathrm{~m}$ and $275 \pm 20 \mathrm{~m}$. In 2001, another distance, $500 \pm 20 \mathrm{~m}$, was added to the design. Downcurrent release positions at distances of 75, 275 and $500 \mathrm{~m}$ were determined by dropping a drogue next to the buoy and recording the initial position with a GPS. When the drogue had drifted down-current for 20 to 30 min or further than $300 \mathrm{~m}$, it was retrieved and a final GPS position taken. The boat was then driven in a straight line towards the FAD, marking GPS positions 275 and $75 \mathrm{~m}$ away. To determine the release points at $500 \mathrm{~m}$ down-current and $275 \mathrm{~m}$ down-current on days when the drogue did not drift beyond $300 \mathrm{~m}$, these points were marked by extrapolating in a direct line from the experimental FAD through the final drogue position. Once the down-current direction had been determined, $20 \mathrm{~m}$ across- and down-current release positions were estimated visually. The 75, 275 and $500 \mathrm{~m}$ across-current release sites were located at right angles to the down-current direction with distances measured out from the FAD by GPS. Fish were released at these marks.

We followed a release protocol to ensure that biases were not introduced into the experiment. Fish that were deeply hooked, bleeding or visibly fatigued were not used. Fish were held on board for between 3 to $5 \mathrm{~min}$ before release, as this was approximately the amount of time taken to travel to the furthest release distance $(500 \mathrm{~m})$. The order of release was randomised within each experimental day and fish were released on alternate sides of the boat, with the boat positioned perpendicular to the release direction, to control for any bias in immediate post-release swimming direction. In 2001, the immediate swimming direction and behaviour of fish upon release was recorded.

Between $1 \frac{1}{2} 2$ and $2 \mathrm{~h}$ after the last fish was released, 6 drift dives on snorkel lasting approx. $1 \mathrm{~h}$ were performed per FAD (approx. $50 \mathrm{~m}$ up-current to $50 \mathrm{~m}$ down-current) to search for tagged returnees. Visibility varied from 20 to $30 \mathrm{~m}$ on experimental days. Tag colours could be clearly seen underwater to a distance of $15 \mathrm{~m}$. A visual census of the species, number and size of fish associated with the FAD was conducted simultaneously.

Data analysis. Analyses of variance (1-factor ANOVAs) were used to determine if SSTs, current speeds and abundances of Coryphaena hippurus and Seriola lalandi differed on experimental days among years. As the number of experimental days differed among years, average values were used to replace missing values to balance ANOVAs and the degrees of freedom were reduced appropriately (Underwood 1997). Post-hoc Student-Newman-Keuls (SNK) tests were used if significant differences were found among years.

Goodness-of-fit 'G-tests' of observed and expected proportions of tagged fish that returned and did not return from different distances were performed for both Coryphaena hippurus and Seriola lalandi. Expected proportions of return and no return at each distance were derived from the 'release angles' model in Fig. 2. The distribution of $G$ is approximated by the $\chi^{2}$-distribution when sample sizes are $>5$ (Sokal \& Rohlf 1981), as in all of our tests.

To test the null hypothesis model that the proportion of tagged fish that returned to FADs is independent of release direction (across- or down-current), G-tests of independence were used. Comparisons were made using the proportions of return and no return of tagged fish between across- and down-current release directions at each distance. For comparisons at $500 \mathrm{~m}$ for Coryphaena hippurus and all distances for Seriola lalandi, we used Yate's correction for continuity, which is a conservative measure recommended for small sample sizes to reduce Type I error (Sokal \& Rohlf 1981).

\section{RESULTS}

\section{Physical and biological variables on experimental days}

Abundances of Coryphaena hippurus on experimental days varied between years, with abundances around FADs in 2000 (mean $\pm \mathrm{SE}=125.0 \pm 22.2$ ) significantly greater than in $2001(48.9 \pm 12.9)$, though not significantly greater than in 2002 (87.0 \pm 37.7 ; Table 1, Fig. 3a). Seriola lalandi (Fig. 3b) was particularly abundant in $2002(55.8 \pm 21.4)$, with few individuals seen at FADs in $2000(6.6 \pm 2.2)$ and $2001(3.9 \pm 0.5)$.

Average daily SSTs recorded at FADs during the study period varied from 20.7 to $24.8^{\circ} \mathrm{C}$. SSTs were significantly greater on experimental days in $2001\left(23.2^{\circ} \mathrm{C} \pm\right.$ $0.2)$, than in both $2000(21.9 \pm 0.2)$ and $2002(22.3 \pm 0.6$; Table 1). However, differences in SSTs among years did not explain variability of Coryphaena hippurus and Seriola lalandi among years, as abundances of these 2 species showed no significant patterns with respect to temperatures (Fig. 4a,c). Moreover, current speed and SST were not correlated on experimental days.

In summer and autumn in all years, current direction varied little, flowing predominantly southwards at speeds between 0.01 to $0.86 \mathrm{~m} \mathrm{~s}^{-1}$. Currents were fastest in $2000\left(0.46 \mathrm{~m} \mathrm{~s}^{-1} \pm 0.06\right)$, weakest in $2001\left(0.13 \mathrm{~m} \mathrm{~s}^{-1} \pm\right.$ 
Table 1. Coryphaena hippurus and Seriola lalandi. Environmental variables and fish abundances at fish aggregation devices (FADs) on days that the experiment was conducted over the 3 yr. Values are means \pm standard error. 'Days' indicates the number of days on which experimental releases were made. Mean-square (MS) and $F$-values $(F)$ are given for ANOVAs comparing environmental variables and fish abundances on experimental days among years. ${ }^{*}=$ significant at $\mathrm{p}=0.05,{ }^{* *}=\operatorname{significant}$ at $\mathrm{p}=0.001 . \mathrm{df}=$ degrees of freedom

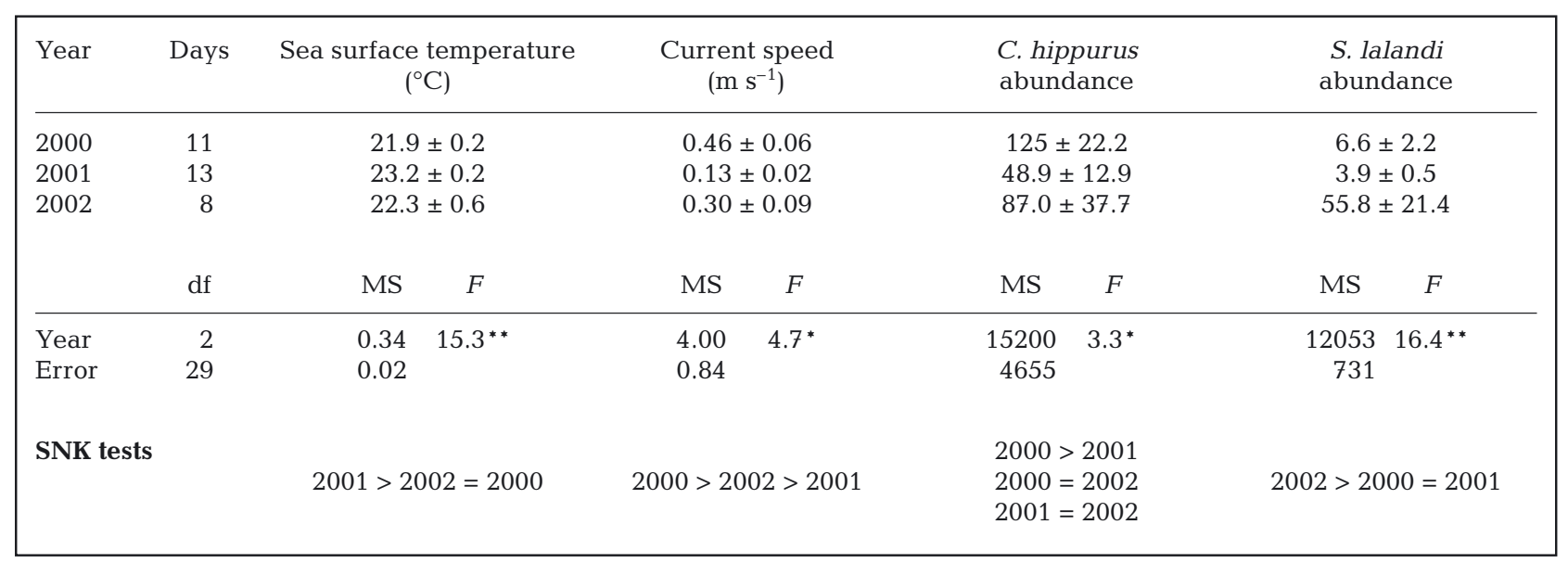

(a) Coryphaena hippurus

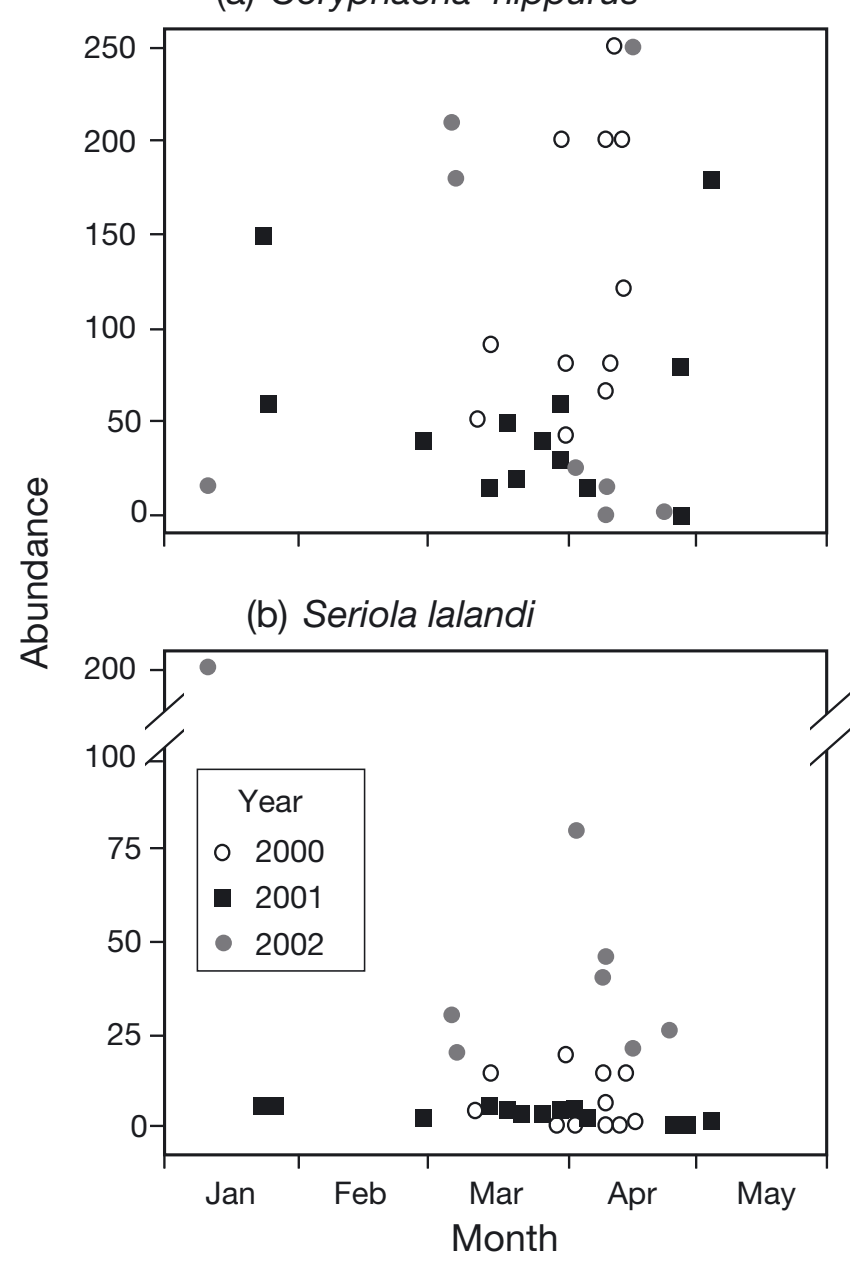

Fig. 3. Abundances of (a) Coryphaena hippurus and (b) Seriola lalandi from visual counts at fish aggregation devices

(FADs) on experimental days in 2000, 2001 and 2002
0.02 ) and speeds were intermediate between these 2 years in $2002\left(0.30 \mathrm{~m} \mathrm{~s}^{-1} \pm 0.09\right.$; Table 1$)$. Variability in current strengths may have influenced abundances of Coryphaena hippurus seen at FADs on experimental days between years. There was a significant relationship between abundance of $C$. hippurus around FADs and current strength $\left(F_{(1,30)}=13.87, \mathrm{p}<0.001, \mathrm{r}^{2}=0.32\right.$; Fig. 4 b). In contrast, there was no significant relationship between current strength and abundance of Seriola lalandi $\left(F_{(1,30)}=0.07, \mathrm{p}=0.79, \mathrm{r}^{2}=0.002\right.$; Fig. $\left.4 \mathrm{~d}\right)$.

The gooseneck barnacle Lepas australis was the only fouling organism found on the under-surfaces of FADs. Barnacles were confined to the submerged part of the buoy and the first $5 \mathrm{~m}$ of mooring line. The level of $L$. australis fouling did not differ between years; FADs had $100 \%$ fouling cover of $L$. australis for all replicate quadrats on all experimental days.

\section{Immediate post-release behaviour and recapture}

Rates of return varied between species and among years; the overall percentage of Seriola lalandi that returned $(67.7 \%$, Table 2) was far greater than for Coryphaena hippurus (26.1\%). Further, the percentage of $C$. hippurus that returned varied substantially between years ( 7.6 to $48.3 \%$ ). Upon release, all fish swam immediately away from the boat beyond visual range and as the boat was driven away at speed (20 to $40 \mathrm{~km} \mathrm{~h}^{-1}$ ), we assume fish did not associate with the boat. Of the 79 fish released in 2001, $72 \%$ swam away at right angles to the boat, $18 \%$ swam parallel to the boat and $10 \%$ swam downwards and out of visual range so no immediate post-release direction could be determined. 
Coryphaena hippurus

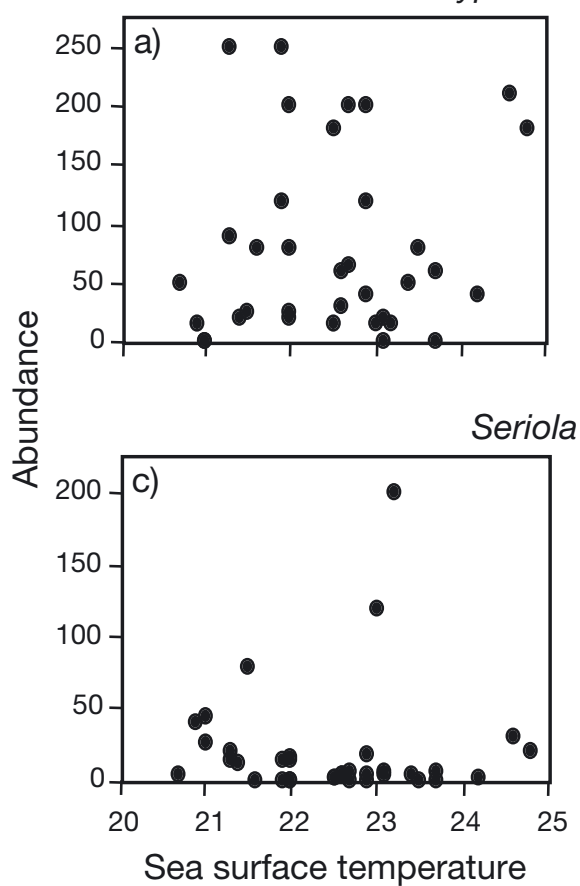

$\left({ }^{\circ} \mathrm{C}\right)$
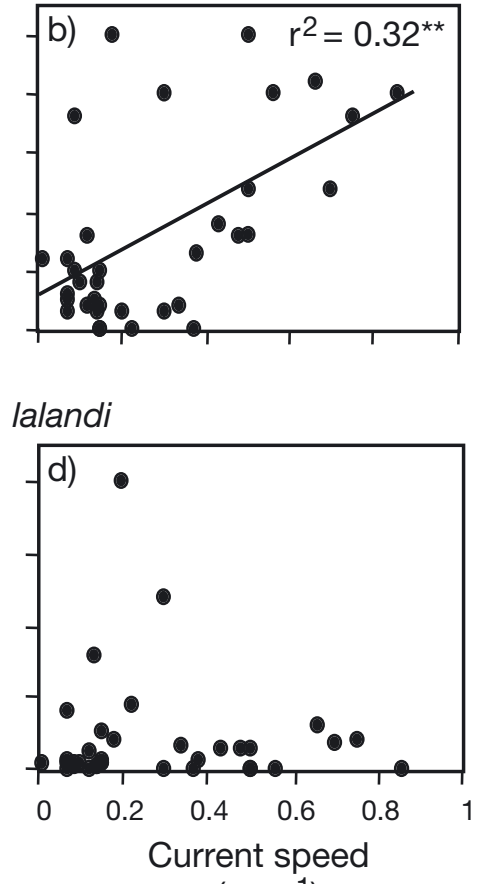

$\left(\mathrm{m} \mathrm{s}^{-1}\right)$
Fig. 4. Abundances of Coryphaena hippurus and Seriola lalandi at fish aggregation devices on experimental days against sea surface temperature $\left({ }^{\circ} \mathrm{C}\right)$ and current speed $\left(\mathrm{m} \mathrm{s}^{-1}\right)$

Table 2. Coryphaena hippurus and Seriola lalandi. Number of tagged fish that returned to fish aggregation devices (FADs) and the percent returned in the 3 experimental years

\begin{tabular}{|lrrrrrr|}
\hline \multirow{2}{*}{ Year } & \multicolumn{3}{c}{ Coryphaena hippurus } & \multicolumn{3}{c|}{ Seriola lalandi } \\
& Tagged & Returned & $\%$ & Tagged & Returned & $\%$ \\
\hline 2000 & 58 & 28 & 48.3 & 3 & 3 & 100 \\
2001 & 79 & 6 & 7.6 & 0 & 0 & - \\
2002 & 24 & 8 & 33.3 & 28 & 18 & 64.3 \\
All years & 161 & 42 & 26.1 & 31 & 21 & 67.7 \\
\hline
\end{tabular}

Table 3. Coryphaena hippurus and Seriola lalandi. G-tests comparing observed and expected returns (from the random direction swimming model; Fig. 2) at the various release distances for $C$. hippurus and S. lalandi. ${ }^{*}=$ significant at $\mathrm{p}=0.05,{ }^{* *}=$ significant at $\mathrm{p}=0.01,{ }^{* * *}=$ significant at $\mathrm{p}=0.001$, ${ }^{\mathrm{ns}}=$ no significant difference

\begin{tabular}{|ccccccc|}
\hline $\begin{array}{c}\text { Release } \\
\text { distance } \\
(\mathrm{m})\end{array}$ & \multicolumn{2}{c}{$\begin{array}{c}\text { Coryphaena hippurus } \\
\text { Observed } \\
\text { returns }\end{array}$} & $\begin{array}{c}\text { Expected } \\
\text { returns }\end{array}$ & $G$ & \multicolumn{3}{c|}{$\begin{array}{c}\text { Seriola lalandi } \\
\text { Observed Expected } \\
\text { returns }\end{array}$} & $\begin{array}{c}\text { Exeturns } \\
\text { return }\end{array}$ \\
\hline 20 & 16 & 13.3 & $0.47^{\mathrm{ns}}$ & 7 & 3.75 & $3.28^{*}$ \\
75 & 13 & 4.7 & $11.13^{* * *}$ & 6 & 0.58 & $24.30^{* * *}$ \\
275 & 13 & 0.9 & $48.16^{* * *}$ & 8 & 0.21 & $54.12^{* * *}$ \\
500 & 0 & 0.10 & $0.21^{\mathrm{ns}}$ & & & \\
\hline
\end{tabular}

\section{Comparison of observed and expected proportions of return}

Homing from particular distances was not due to a random swimming direction from the point of release. For Coryphaena hippurus, observed proportions of return were not significantly different from expected proportions of return from $20 \mathrm{~m}$ $(G=0.5, \mathrm{p}>0.05$, Table 3). However, from $75 \mathrm{~m}(G=11.1, \mathrm{p}<0.001)$ and $275 \mathrm{~m}$ $(G=48.2, \mathrm{p}<0.001), \quad C$. hippurus returned in proportions far greater than could be expected due to chance. We concluded, therefore, that fish had a directed homing behaviour to FADs. From $500 \mathrm{~m}$, no C. hippurus returned to FADs and observed and expected proportions of return did not differ $(G=0.2$, $\mathrm{p}>0.05)$, although only 8 fish were released from this distance. Homing of Seriola lalandi to FADs was a nonrandom process at 20,75 and $275 \mathrm{~m}$, with observed proportions of return significantly greater than expected values (20 m: $G=3.28, \mathrm{p}<0.05 ; 75 \mathrm{~m}: G=24.3$, $\mathrm{p}<0.001 ; 275 \mathrm{~m}: G=54.1, \mathrm{p}<0.001)$.

\section{Comparison of down- and across- current proportions of return}

Proportions of returns pooled across the 3 years for Coryphaena hippurus varied from 18 to $33 \%$ at across-current release sites and 29 to $35 \%$ at down-current release sites (Fig. 5a). Proportions of returns from the various release distances differed greatly among the 3 study years, with returns highest in 2000 (Fig. 5b, 27 to $70 \%$ ), lowest in 2001 (Fig. 5c, 0 to $22 \%$ ) and intermediate (Fig. $5 \mathrm{~d}, 0$ to $67 \%$ ) in 2002. Notably, returns were only recorded from the 20 or $75 \mathrm{~m}$ release distances in 2001, with no C. hippurus returning from either of the $275 \mathrm{~m}$ downor across-current release sites. For Seriola lalandi, proportions of returns pooled across the 3 years ranged between 40 and $100 \%$ at across-current release sites and 60 to $100 \%$ at down-current release sites (Fig. 5e).

$G$-tests of independence were used to determine whether the proportions of tagged fish pooled across the 3 years that 
(a) Coryphaena hippurus all years

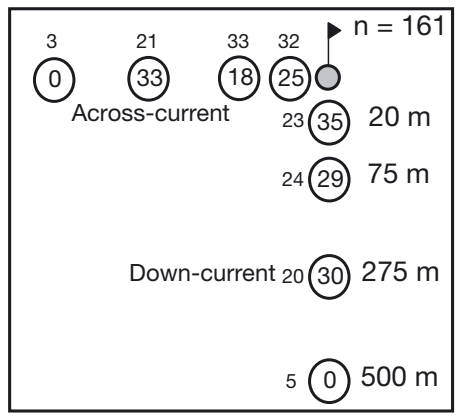

(c) C. hippurus 2001

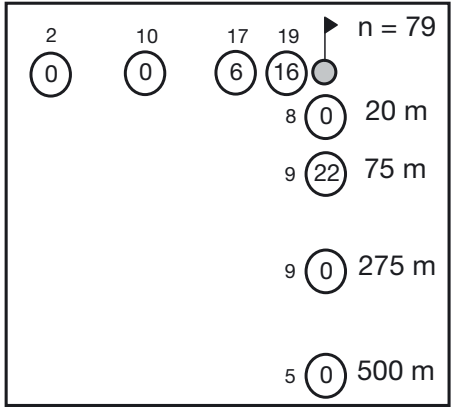

(e) Seriolalalandi all years

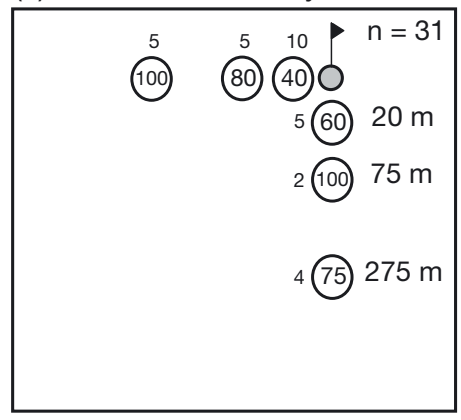

(b) C. hippurus 2000

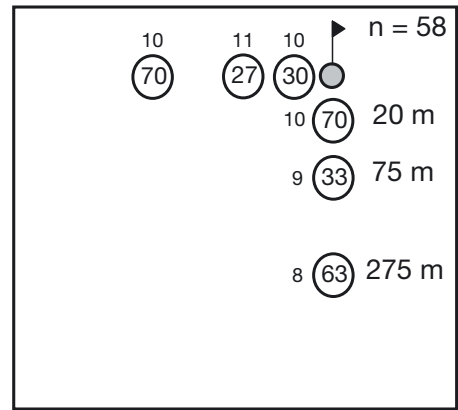

(d) C. hippurus 2002

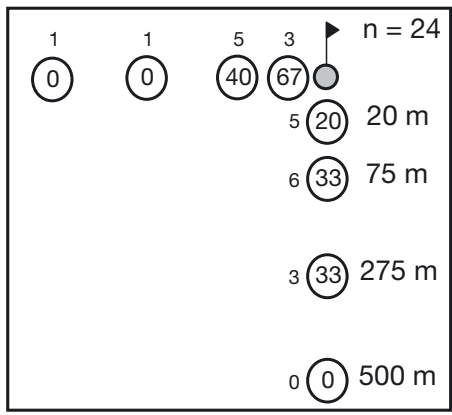

Fig. 5. Coryphaena hippurus and Seriola lalandi. Percentages of fishes visually recaptured at fish aggregation devices (FADs) (numbers in circles) after release at 20, 75,275 and $500 \mathrm{~m}$ distance for (a) C. hippurus all years, (b) C. hippurus 2000, (c) C. hippurus 2001, (d) C. hippurus 2002 and (e) $S$. lalandi all years. $\mathrm{n}=$ overall number of fish released for each plot. Small numbers above (across-current) and beside (down-current) each circle give the number of fish released in each treatment

\section{DISCUSSION}

\section{Experimental technique}

Recapture rates of fish varied among years, possibly due to differences in current strength among years. Returns of Coryphaena hippurus were highest in 2000 and 2002 when currents were strongest, with lowest returns in 2001 when currents were weak. Far more C. hippurus were observed at FADs when currents were strong, indicating either greater numbers at FADs during strong currents or a behavioural shift toward closer association with FADs. The latter case would explain the high proportions of return in 2000 and 2002, and comparatively poor returns in 2001. Sea surface temperature appeared to have no influence on the proportion of fish returning among years, as C. hippurus abundances were not related to SSTs, and temperature and current were independent on experimental days. Moreover, SSTs were consistently above $20^{\circ} \mathrm{C}$, which is widely observed as the minimum threshold temperature of appearance for C. hippurus (Goldberg \& Aguilar 1985, Norton 1999, Bennett 2001).

Despite differences in recapture rates among years, there is no reason to suggest that variation in current strengths differentially affected return rates of fish released at different distances or in different directions (down- or across-current). As such, our tests for random or directed swimming behaviour and the influence of chemical cues are valid. Moreover, although our experimental returned to FADs were independent of release direction (Table 4). Paired comparisons for the down- and across-current release directions indicated that proportions of return were similar at all distances for both Coryphaena hippurus $(G<1, \mathrm{p}>0.1$ in all cases) and Seriola lalandi $(G<2, \mathrm{p}>0.05$ in all cases). Based on this analysis, we reject our hypothesis that fish released down-current of FADs, where chemical cues are likely to be present, return to FADs in higher proportions than fish released acrosscurrent. The displacement experiments, therefore, provide no evidence to suggest that chemical cues influence homing of $C$. hippurus or S. lalandi to FADs.
Table 4. G-tests of independence comparing returns and no returns between across- and down-current release points at each distance for Coryphaena hippurus and Seriola lalandi. ${ }^{\text {ns }}=$ no significant difference

\begin{tabular}{|lccccccc|}
\hline \multirow{2}{*}{$\begin{array}{l}\text { Release } \\
\text { point }\end{array}$} & \multicolumn{3}{c}{ Coryphaena hippurus } & \multicolumn{3}{c|}{ Seriola lalandi } \\
comparisons & Return & No & $G$ & Return & No & $G$ \\
& \multicolumn{2}{c}{ return } & & \multicolumn{4}{c}{ return } \\
\hline $20 \mathrm{~m}$ down & 8 & 15 & $0.62^{\mathrm{ns}}$ & 3 & 2 & $0.54^{\mathrm{ns}}$ \\
$20 \mathrm{~m}$ across & 8 & 24 & & 4 & 6 & \\
$75 \mathrm{~m}$ down & 7 & 17 & $0.94^{\mathrm{ns}}$ & 3 & 1 & $0.02^{\mathrm{ns}}$ \\
$75 \mathrm{~m}$ across & 6 & 27 & & 4 & 1 & \\
$275 \mathrm{~m}$ down & 6 & 14 & $0.05^{\mathrm{ns}}$ & 3 & 1 & $1.78^{\mathrm{ns}}$ \\
$275 \mathrm{~m}$ across & 7 & 14 & & 5 & 0 & \\
$500 \mathrm{~m}$ down & 0 & 5 & $0.00^{\mathrm{ns}}$ & & & \\
$500 \mathrm{~m}$ across & 0 & 3 & & & & \\
\hline
\end{tabular}


technique is limited by both the lack of information regarding return route and its labour-intensive nature (Quinn \& Dittman 1992), the high rate of returns observed compared to other methods such as conventional tag and recapture (Coryphaena hippurus 1\% recapture, Kingsford \& Defries 1999; Seriola lalandi $8 \%$ recapture, Gillanders et al. 2001), and low cost (approx. $\$ 1 \mathrm{tag}^{-1}$ ), operational simplicity and the high replication possible compared to ultrasonic tagging and tracking make it appropriate for testing specific hypotheses concerning the behaviour of pelagic fish over the spatial scale of 100 s of meters Listening stations and 'chat' tags (Klimley \& Holloway 1999) may also be appropriate for testing such hypotheses.

\section{Homing of Coryphaena hippurus and Seriola lalandi to FADs}

Both Coryphaena hippurus and Seriola lalandi exhibited a directed homing behaviour toward FADs, returning in significantly greater numbers than could be expected if movement from the point of release occurred in a random direction. Although the association of C. hippurus and Seriola sp. with FADs is well known, our study provides the first evidence of homing in these taxa. Based on observational evidence, homing to FADs has been demonstrated from distances of 5 to 8 nautical miles for large pelagic species, such as yellowfin Thunnus albacares (Holland et al. 1990, Cayre 1991, Marsac \& Cayre 1998; Brill et al. 1999) and bigeye tuna T. obesus (Holland et al. 1990) and shorter distances of up to $180 \mathrm{~m}$ for small FAD-associated fish such as the unicorn filefish Alutera monoceros and black-banded trevally Seriolina nigrofasciata (Ibrahim et al. 1990). In the present study, both C. hippurus and $S$. lalandi homed from a minimum of $275 \mathrm{~m}$ from FADs. While no C. hippurus or S. lalandi were observed to return from $500 \mathrm{~m}$ release sites, we cannot rule out that fish may reassociate from this distance due to the small number of releases made at distances over $275 \mathrm{~m}$. Holland et al. (1990) demonstrated that tuna make significant excursions from FADs and return to them. Recapture data for $C$. hippurus and S. lalandi indicate they can remain near FADs for days to weeks (Dempster 2003). Both species appear capable of making excursions from FADs, at least at the scale of 100s of meters, and returning.

\section{Role of sensory processes in homing behaviour}

Chemical cues are believed important in the homing behaviour of many different types of fish over large (10s to 100s of kilometers; Bjerselius et al. 2000, Doving
\& Stabell 2003) and small spatial scales (meters; Elliot et al. 1995). While we know of no studies that describe the olfactory capabilities of Coryphaena hippurus and Seriola lalandi, other large FAD-associated species can detect certain compounds at extremely low concentrations (Kobayashi \& Fujiwara 1987, Atema et al. 1980). Fouling organisms on FADs and fish associated with FADs are likely to produce amino acids, which may provide a persistent chemical signature at concentrations above the detection thresholds of pelagic fish downstream for meters to 100 s of meters. The displacement experiment, however, provided no evidence to suggest that $C$. hippurus and S. lalandi only used chemical cues to home to FADs. Returns from down- and across-current release sites were similar at all distances for both species. Other senses used by fish for navigation must have played a more important role at the spatial scale and ecological context of our experiment.

Perhaps the greatest limitation of the conventional tag and visual recapture technique is the lack of information on return route. We do not know whether fish released across-current searched for FADs differently or took longer to re-associate than fish released downcurrent, both of which may indicate some influence of chemical cues upon homing. Such information can only be generated by ultrasonic tagging and tracking of individual fish. However, it is difficult to conceive of a functional system in deep water $(>100 \mathrm{~m})$ in the open ocean whereby ultrasonic tags could provide useful information on movements of pelagic fish around FADs over the scale of meters, as an array of receivers would be required to triangulate positions accurately. The receivers must be placed under moored buoys or boats, which may themselves attract the released fish (Dagorn et al. 2001).

As Coryphaena hippurus and Seriola lalandi homed from minimum distances of up to $275 \mathrm{~m}$ away, sensory processes other than vision and olfaction, such as sound and infrasound, may operate. Detection of low frequency sounds from the FAD mooring line has been suggested as a possible navigational cue (Marsac \& Cayre 1998) and FAD-associated fish may also produce sound. Possible auditory cues from FADs are likely to be detectable over meters to kilometers (Kingsford et al. 2002) and sound propagates equally in all directions in water (Hawkins 1993). The similar rates of return observed for $C$. hippurus and S. lalandi from both across- and down-current is consistent with homing in response to sound emanating from FADs. Moreover, strong currents cause mooring lines to vibrate with greater intensity and FADs to become 'louder', increasing the ability of detection of FAD sound above background noise (Popper et al. 2003). Our results showed rates of return were highest in 
years when currents were strong (2000 and 2002), with few returns in 2001 when currents were weak. However, whether fish can localise sound with sufficient sensitivity to navigate by is not yet established (Popper et al. 2003), although Kalmijn (1997) proposed that fish might navigate by maintaining a particular swimming direction relative to an incoming sound. Further physiological work and field experiments are necessary to determine the role of sound, if any, in the navigation of pelagic fish to FADs.

Magnetic cues have long been thought important in navigation for many animals, although the detection mechanism remains unknown (Walker et al. 1997). Yellowfin tuna Thunnus albacares, which often associate with FADs, may navigate by using cranial magnetic sense organs (Walker et al. 1984) and a 'magnetic map' (Walker et al. 1997). Magnetic cues may feasibly play a role in homing to the general area of FADs from distances of kilometers to 10 s of kilometers. However, such a mechanism is likely to be useless for homing by pelagic fish over the spatial scale of 100s of meters of our experimental releases. Moreover, the continental shelf off Sydney is sediment-laden and without obvious geological anomalies (e.g. volcanic ridges; Klimley 1993) that would produce distinct magnetic signals.

\section{Conclusions}

Several previous studies have described homing behaviour of pelagic fish to FADs, though none has done so within an experimental framework designed to test hypotheses regarding possible cues. To our knowledge, this is the first manipulative experiment to examine the possible roles of sensory cues in homing behaviour of pelagic fish to FADs. We have demonstrated that Coryphaena hippurus and Seriola lalandi can detect FADs from 10s to 100s of meters away, well outside the visual range of fish. A simple model of chemotaxis did not explain the patterns of recapture we found, and we suggest that vibrations from the FADs or associated fish are likely to be important cues. We concur with the suggestion of Dagorn et al. (2000) that future experiments must take a similarly manipulative approach, testing specific hypotheses against controls, to elucidate processes underpinning the attraction and association of pelagic fish with FADs.

Classical experiments involving sensory ablation, either through cutting of nerves (Craigie 1926) or otherwise disabling sensory organs (Hiyama et al. 1966, Groves et al. 1968), may be impractical for large pelagic fish due to the stress such procedures induce. However, non-surgical solutions such as rapid blocking of the nares with a biologically neutral, fastsetting compound to inhibit the sense of smell ( $\mathrm{K}$.
Doving pers. comm.) or attaching small magnets to confuse possible magneto-receptors may be feasible, and appropriate controls can be made. Coupling such manipulations with field experiments using tags and visual recapture over the scale of 100 s of meters and ultrasonic tracking over kilometers will provide more information on the roles of various sensory cues in homing of pelagic fish to FADs.

Acknowledgements. We would like to thank the many volunteers who helped with tagging, in particular S. Long, J. Hughes, S. Dworjanyn, M. Letnic, M. Tischler and P. Schupp. H. Patterson and J. Hughes improved early drafts of the manuscript. New South Wales Fisheries kindly provided the tags used for the project from the Recreational Gamefish Tagging Program. Manly Hydraulics Laboratory (New South Wales Department of Public Works and Services) provided the temperature data from the FADs. T.D. acknowledges funding from an Australian Postgraduate Award towards this research.

\section{LITERATURE CITED}

Atema J, Holland K, Ikehara W (1980) Olfactory responses of yellowfin tuna (Thunnus albacares) to prey odors: chemical search image. J Chem Ecol 6:457-465

Bennett J (2001) The ecology of dolphin fish (Coryphaena hippurus) off the coast of New South Wales, inferred from tag and release data. BSc thesis, University of New South Wales, Sydney

Bjerselius R, Li W, Teeter JH, Seelye JG and 5 others (2000) Direct behavioural evidence that unique bile acids released by larval sea lamprey (Petromyzon marinus) function as a migratory pheremone. Can J Fish Aquat Sci 57:557-569

Brill RW, Block BA, Boggs $\mathrm{CH}$, Bigelow KA, Freund EV, Marcinek DJ (1999) Horizontal movements and depth distribution of large adult yellowfin tuna (Thunnus albacares) near the Hawaiian Islands, recorded using ultrasonic telemetry: implications of the physiological ecology of pelagic fishes. Mar Biol 133:395-408

Cayre P (1991) Behaviour of yellowfin tuna (Thunnus albacares) and skipjack tuna (Katsuwonus pelamis) around fish aggregating devices (FADs) in the Comoros Islands as determined by ultra-sonic tagging. Aquat Living Resour $4: 1-12$

Craigie EH (1926) A preliminary experiment upon the relation of the olfactory sense to the migration of the sockeye salmon (Oncorhynchus nerka Walbaum). Trans R Soc Can 20:215-224

Dagorn L, Josse E, Bach P (2000) Individual differences in horizontal movements of yellowfin tuna (Thunnus albacares) in nearshore areas in French Polynesia, determined using ultrasonic telemetry. Aquat Living Resour 13:193-202

Dagorn L, Josse E, Bach P (2001) Association of yellowfin tuna (Thunnus albacares) with tracking vessels during ultrasonic telemetry experiments. Fish Bull 99:40-48

Dempster T (2003) Association of pelagic fish with floating structures: patterns, processes and ecological consequences. PhD thesis, University of Sydney

Doving K, Stabell OB (2003) Trails in open water: sensory cues in salmon migration. In: Collin SP, Marshall NJ (eds) Sensory processing in aquatic environments. Springer- 
Verlag, New York, p 39-52

Elliott JK, Elliott JM, Marsical RN (1995) Host selection, location, and association behaviors of anemonefishes in field settlement experiments. Mar Biol 122:377-389

Fonteneau A, Pallares P, Pianet R (2000) A worldwide review of purse seine fisheries on FADs. In: Le Gall JY, Cayre $\mathrm{P}$, Taquet $\mathrm{M}$ (eds) Pêche thonière et dispositifs de concentration de poissons. IFREMER, Caraibe-Martinique, p 15-34

Gillanders BM, Ferrell DL, Andrew NL (2001) Estimates of movement and life-history parameters of yellowtail kingfish (Seriola lalandi): how useful are data from a cooperative tagging programme? Mar Freshw Res 52:1-14

Goldberg SR, Aguilar AT (1985) Notes on spawning in the dolphinfish Coryphaena hippurus (Coryphaenidae) from Peru. Bull S C Acad Sci 84:51-52

Groves AB, Collins GB, Trefethen GB (1968) Roles of olfaction and vision in choice of spawning site by homing adult chinook salmon (Oncorhynchus tshawytscha). J Fish Res Bd Can 25:867-876

Hawkins AD (1993) Underwater sound and fish behaviour. In: Pitcher TJ (ed) Behaviour of teleost fishes, 2nd edn. Chapman \& Hall, London, p 129-169

Higashi GR (1994) Ten years of fish aggregation device (FAD) design development in Hawaii. Bull Mar Sci 55(2-3): 651-666

Hiyama Y, Taniuchi T, Suyama K (1966) A preliminary experiment on the return of tagged chum salmon to the Otsuchi River, Japan. Jpn Soc Sci Fish 33:18-19

Holland K, Brill R, Chang R (1990) Horizontal and vertical movements of yellowfin and bigeye tuna associated with fish aggregating devices. Fish Bull 88(3):493-507

Hunter JR, Mitchell CT (1967) Association of fishes with flotsam in the offshore waters of central America. Fish Bull 66(1):13-29

Ibrahim S, Kawamura G, Ambak MA (1990) Effective range of traditional Malaysian FAD as determined by fish releasing method. Fish Res 9:299-306

Kalmijn AJ (1997) Electric and near-field acoustic detection, a comparative study. Acta Physiol Scand 161:25-38

Kingsford MJ (1993) Biotic and abiotic structure in the pelagic environment: importance to small fish. Bull Mar Sci 53: 393-415

Kingsford MJ (1999) Fish attraction devices (FADs) and experimental designs. Sci Mar 63(3-4):181-190

Kingsford MJ, Defries A (1999) The ecology of and fishery for Coryphaena spp. in the waters around Australia and New Zealand. Sci Mar 63(3-4):267-275

Kingsford M, Leis J, Shanks A, Lindeman K, Morgan S, Pineda J (2002) Sensory environments, larval abilities and local self-recruitment. Bull Mar Sci 70(1):341-375

Klimley AP (1993) Highly directional swimming by scalloped

Editorial responsibility: Otto Kinne (Editor), Oldendorf/Luhe, Germany hammerhead sharks, Sphyrna lewini, and subsurface irradiance, temperature, bathymetry and geomagnetic field. Mar Biol 117(1):1-22

Klimley AP, Holloway CF (1999) School fidelity and homing synchronicity of yellowfin tuna Thunnus albacares. Mar Biol 133:307-317

Kobayashi H, Fujiwara K (1987) Olfactory response in the yellowtail Seriola quinqueradiata. Nippon Suisan Gakkaishi 53:1717-1725

Lohmann KJ, Lohmann CMF (1996) Detection of magnetic field intensity by sea turtles. Nature 380:59-61

Lowry MB, Suthers IM (1998) Home range, activity and distribution patterns of a temperate rocky-reef fish, Cheilodactylus fuscus. Mar Biol 132(4):569-578

Marsac F, Cayre P (1998) Telemetry applied to behaviour of yellowfin tuna (Thunnus albacares, Bonnaterre, 1788) movements in a network of fish aggregating devices. Hydrobiologia 371/372:155-171

Nakamura EI (1968) Visual acuity of two tunas, Katsuwonus pelamis and Euthynnus affinis. Copeia 1:41-49

Northmore D, Volkmann FC, Yager D (1978) Vision in fishes: color and pattern. In: Mostofsky DI (ed) The behavior of fish and other aquatic animals. Academic Press, London, p 79-136

Norton JG (1999) Apparent habitat extensions of dolphin-fish (Coryphaena hippurus) in response to climate transients in the California Current. Sci Mar 63(3-4):239-260

Papi F (1992) General aspects. In: Papi F (ed) Animal homing. Chapman \& Hall, London, p 1-18

Popper AN, Fay RR, Platt C, Sand O (2003) Sound detection mechanisms and capabilities of teleost fishes. In: Collin SP, Marshall NJ (eds) Sensory processing in aquatic environments. Springer-Verlag, New York, p 3-38

Quinn TP, Merrill RT, Brannon EL (1981) Magnetic field detection in sockeye salmon. J Exp Zool 217:137-142

Quinn TP, Dittman AH (1992) Fishes. In: Papi F (ed) Animal homing. Chapman \& Hall, London, p 145-211

Sokal RR, Rohlf FJ (1981) Biometry: the principles and practice of statistics in biological research. WH Freeman, San Francisco

Underwood AJ (1997) Experiments in ecology: their logical design and interpretation using analysis of variance. Cambridge University Press, Cambridge

Walker MM (1984) Learned magnetic field description in the yellowfin tuna, Thunnus albacares. J Comp Physiol A 155: 673-679

Walker MM, Kirschvink JL, Dizon AE (1984) A candidate magnetic sense organ in the yellowfin tuna, Thunnus albacares. Science 224:751-753

Walker MM, Diebel CE, Haugh CV, Pankhurst PM, Montgomery JC, Green CR (1997) Structure and function of the vertebrate magnetic sense. Nature 390:371-376

Submitted: October 1, 2002; Accepted: April 3, 2003

Proofs received from author(s): August 12, 2003 